\title{
UPAYA PENINGKATAN KESEHATAN GIGI DAN MULUT ANAK PENDERITA TUNA GRAHITA DAN TUNA RUNGU MELALUI PEMERIKSAAN, PENYULUHAN DAN DEMONSTRASI MENYIKAT GIGI DI SLB SWADAYA ABC KENDAL
}

\author{
Risyandi Anwar ${ }^{1^{*}}$, Tyas Nurfadliah Amaliah ${ }^{2}$ \\ ${ }^{1,2}$ Universitas Muhammadiyah Semarang \\ Email Korespondensi: drg.risyandi@unimus.ac.id

\begin{abstract}
ABSTRAK
Anak berkebutuhan khusus memiliki keterbelakangan mental dan kekurangan secara fisik, dan sebagian besar memiliki kesehatan gigi dan mulut yang buruk. Beberapa yang termasuk katagori $A B K$ adalah tunagrahita dan tuna rungu. Keterbatasan dalam menjaga kesehatan gigi dan mulut sering dialami pada anak berkebutuhan khusus baik laki-laki maupun perempuan, oleh karena itu mereka sangat memerlukan dukungan sosial dari lingkungannya agar dapat mencapai kemampuan fungsional setinggi mungkin. Tujuan Pengabdian kepada masyarakat ini adalah setelah mendapatkan pemeriksaan, penyuluhan dan demonstrasi diharapkan semua penderita tuna grahita dan tuna rungu yang ada di SLB swadaya $A B C$ dan pendampingnya dapat memahami dan menerapkan cara menyikat gigi yang baik dan benar sehingga dapat menjaga kesehatan gigi dan mulut anak penderita tuna grahita dan tuna rungu. Metode kegiatan penyuluhan, demonstrasi dan pemeriksaan gigi dan mulut terhadap semua anak penderita tuna grahita dan tuna rungu yang bersekolah di SLB Swadaya ABC Kendal dan pendampingnya. Luaran yang di harapkan dari kegiatan penyuluhan dan demonstrasi ini adalah adanya peningkatan kesehatan gigi dan mulut anak penderita tuna grahita dan tuna rungu yang bersekolah di SLB Swadaya ABC Kendal. Hasil pelaksanaan didapatkan bahwa lebih dari $50 \%$ anak penderita tuna grahita dan tuna rungu keadaan gigi dan mulutnya buruk. Kesehatan gigi dan mulut penderita tuna grahita dan tuna rungu termasuk dalam kategori sedang.
\end{abstract}

Kata kunci: tuna grahita, tuna rungu, SLB, Penyuluhan, Kesehatan gigi dan mulut.

\begin{abstract}
Children with special needs have mental retardation and most of them have poor oral and dental health. Some spesial needs are mentally disable and deaf. Limitations in maintaining dental and oral health are often experienced by children with special needs, both boys and girls, therefore they really need social support from their environment in order to achieve the highest possible functional ability. These children need special attention in maintaining oral hygiene. The purpose of this community service is that after receiving counseling and demonstrations, it is hoped that all mentally disable and deaf sufferers in the ABC self-help SLB and their companions can understand and apply good and correct brushing techniques so that they can maintain good oral
\end{abstract}


hygiene. Dental and oral health of children with mentally disable and deaf. The target of counseling and demonstration activities are all children with mentally disable and deaf who attend SLB Swadaya ABC Kendal and their companions. The expected outcome of this counseling and demonstration activity is an increase in the oral hygiene of children with mentally disable and deaf who attend SLB Swadaya $A B C$ Kendal. From the results of the implementation, it was found that more than $50 \%$ of children with mentally disable and deaf had bad teeth and mouth conditions. Conclusion: Dental and oral health of people with mentally disable and deaf is in the moderate category.

Key words: Mentally disable, deaf, SLB, Counseling, Dental and oral health.

\section{PENDAHULUAN}

Keterbatasan dalam menjaga kesehatan gigi dan mulut sering dialami pada anak berkebutuhan khusus, baik laki-laki maupun perempuan (Anwar \& Dinastiti, 2022; Tulangow et al., 2015). Mereka sangat memerlukan dukungan sosial dari lingkungannya agar dapat mencapai kemampuan fungsional setinggi mungkin, sehingga anak tersebut membutuhkan perhatian khusus dalam menjaga kebersihan mulut dan dukungan orang tuanya (Adhi \& Octavia, 2013; Ekasari et al., 2019; Maryam, 2008).

Anak berkebutuhan Khusus memiliki keterbelakangan mental dan kekurangan secara fisik, dan sebagian besar memiliki kesehatan gigi dan mulut yang buruk. Beberapa yang termasuk katagori ABK adalah tunagrahita dan tuna rungu (Askiyah, 2017; Lisinus \& Sembiring, 2020). Keterbatasan dalam menjaga kesehatan gigi dan mulut sering dialami pada anak berkebutuhan khusus baik laki-laki maupun perempuan, oleh karena itu mereka sangat memerlukan dukungan sosial dari lingkungannya agar dapat mencapai kemampuan fungsional setinggi mungkin (Dewi \& Ners, 2015; Kurniawan, 2017).

Penderita tuna grahita dan tuna rungu mempunyai susunan geligi yang tidak beraturan, dan ini merupakan faktor predisposisi dari retensi plak dan mempersulit upaya menghilangkan plak (Mawardiyanti, 2012; Taftazani, 2015). Semakin meningkatnya usia, meningkat pula masalah kesehatan gigi dan mulut penderita retardasi mental yang disebabkan tuna grahita dan tuna rungu, sehingga kebutuhan akan perawatan kesehatan gigi dan mulut semakin meningkat sejalan dengan usianya (Mawardiyanti, 2012; Zakiyyah, 2019). Penyuluhan dan demonstrasi merupakan upaya peningkatan promotive dan pencegahan (preventif) Kesehatan gigi dan mulut (Kristianto et al., 2018; Prasko et al., 2016).

Kabupaten Kendal terdapat sebuah SLB yang banyak mendidik siswa tuna grahita dan tuna rungu, yaitu SLB swadaya ABC Kendal. Masalah yang terjadi adalah sangat sedikit sekali perhatian terhadap Kesehatan gigi dan mulut siswa tuna grahita dan tuna rungu di SLB Swadaya ABC Kendal. Berdasarkan hasil wawancara dengan beberapa guru di SLB Swadaya ABC Kendal tersebut, jarang sekali ada pemeriksaan dan penyuluhan Kesehatan gigi dan mulut terhadap siswa SLB Swadaya ABC Kendal tersebut.

\section{MASALAH}

Dari beberapa keterangan diatas maka penulis tertarik untuk melakukan pengabdian kepada masyarakat dengan penyuluhan dan pemeriksaan kebersihan mulut yang berjudul "Upaya Peningkatan Kesehatan Gigi dan Mulut Siswa 
penderita tuna grahita dan tuna rungu melalui pemeriksaan Kesehatan gigi, penyuluhan dan demontrasi cara menyikat gigi di SLB Swadaya ABC Kendal. Berikut peta lokasi kegiatan;

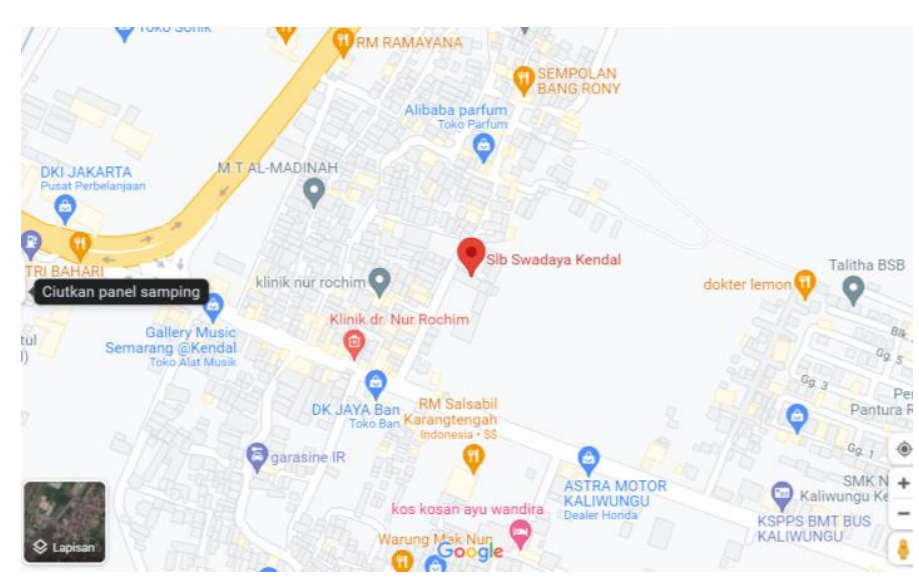

Gambar 1. Peta lokasi kegiatan

\section{METODE}

Metode yang digunakan dalam pengabdian masyarakat ini adalah dengan menggunakan ceramah, demontrasi dan pemeriksaan gigi dan mulut. Metode ini digunakan sebagai pengantar untuk memberikan pengertian dan penekanan pengertian kebersihan gigi dan mulut. Mendemontrasikan cara menyikat gigi dan membersihkan lidah dilakukan saat berlangsungnya penyuluhan mengenai kebersihan gigi dan mulut setelah dilakukan pemeriksaan kebersihan gigi dan mulut dilakukan. Kegiatan Pengabdian Masyarakat melalui pemeriksaan dan penyuluhan Kesehatan gigi dan mulut ini dilaksanakan di SLB Swadaya ABC Kendal pada bulan april 2019.

\section{HASIL DAN PEMBAHASAN}

Pelaksanaan pengabdian masyarakat yang dilakukan oleh Tim Program Studi Pendidikan Dokter Gigi Universitas Muhammadiyah Semarang yaitu kegiataan penyuluhan, demonstrasi dan pemeriksaan Kesehatan gigi dan mulut anak tuna grahita dan tuna rungu di SLB Swadaya ABC Kendal pada bulan april 2019 dan mendapatkan hasil pelaksanaan kegiatan pengabdian masyarakat sudah dilaksanakan dan membawa dampak yang baik bagi anak-anak penderita tuna grahita dan tuna rungu di SLB ABC Kendal dimana mereka mengerti dan melaksanakan kebersihan gigi dan mulutnya. Pelaksanaan pengabdian masyarakat dimulai dari koordinasi internal pelaksanaan pengabdian Bersama beberapa mahasiswa, kemudian koordinasi dengan pimpinan dan guru SLB ABC Kendal, serta pelaksanaan pengabdian sampai pada evaluasi dan pembuatan laporan kegiatan pengabdian pada masyarakat.

Berikut hasil pemeriksaan keberishan gigi dan mulut anak tuna grahita dan tuna rungu SLB ABC Kendal. 
Data KebersihanMulut (OHI-S) Tunagrahita

\begin{tabular}{|c|c|c|c|c|c|c|}
\hline No & Nama & $\begin{array}{c}\text { Usia } \\
\text { (Tahun) }\end{array}$ & Kelas & $\begin{array}{c}\text { Jenis } \\
\text { Kelamin }\end{array}$ & $\begin{array}{l}\text { Skor } \\
\text { OHI-S }\end{array}$ & Kategori \\
\hline 1 & 101 & 8 & $5 C$ & $\mathrm{~L}$ & 3,83 & Buruk \\
\hline 2 & 102 & 10 & $4 C$ & L & 2,33 & Cukup \\
\hline 3 & 103 & 12 & $5 C$ & $P$ & 3,83 & Buruk \\
\hline 4 & 104 & 13 & $5 C$ & $P$ & 3,00 & Cukup \\
\hline 5 & 105 & 13 & $6 C$ & $P$ & 3,5 & Buruk \\
\hline 6 & 106 & 13 & $5 C$ & $P$ & 2,34 & Cukup \\
\hline 7 & 107 & 7 & $4 C$ & $\mathrm{~L}$ & 1,5 & Cukup \\
\hline 8 & 108 & 7 & $4 C$ & $P$ & 3,3 & Buruk \\
\hline 9 & 109 & 8 & $4 C$ & $\mathrm{~L}$ & 2,33 & Cukup \\
\hline 10 & 110 & 13 & $6 C$ & $\mathrm{~L}$ & 3,5 & Buruk \\
\hline 11 & 111 & 8 & $4 C$ & $P$ & 1,99 & Cukup \\
\hline 12 & 112 & 9 & $4 C$ & $P$ & 3,67 & Buruk \\
\hline 13 & 113 & 9 & $4 C$ & $\mathrm{~L}$ & 1,33 & Cukup \\
\hline 14 & 114 & 8 & $4 C$ & $P$ & 2,33 & Cukup \\
\hline 15 & 115 & 11 & $5 C$ & $\mathrm{~L}$ & 3,67 & Buruk \\
\hline 16 & 116 & 10 & $5 C$ & $P$ & 2,67 & Cukup \\
\hline 17 & 117 & 12 & $6 C$ & $\mathrm{~L}$ & 3,23 & Buruk \\
\hline 18 & 118 & 12 & $6 C$ & $P$ & 2,83 & Cukup \\
\hline 19 & 119 & 12 & $5 \mathrm{C}$ & $P$ & 2,67 & Cukup \\
\hline 20 & 120 & 13 & $6 C$ & $P$ & 2,17 & Cukup \\
\hline 21 & 121 & 7 & $4 C$ & $P$ & 2,83 & Cukup \\
\hline 22 & 122 & 8 & $5 C$ & $P$ & 2,66 & Cukup \\
\hline 23 & 123 & 12 & $6 C$ & $P$ & 2,93 & Cukup \\
\hline 24 & 124 & 9 & $4 C$ & $\mathrm{~L}$ & 2,66 & Cukup \\
\hline 25 & 125 & 12 & $6 C$ & $\mathrm{~L}$ & 2,99 & Cukup \\
\hline
\end{tabular}

Data Kebersihan Mulut (OHI-S) Tunarungu

\begin{tabular}{ccccccc}
\hline No & Nama & $\begin{array}{c}\text { Usia } \\
\text { (Tahun) }\end{array}$ & Kelas & $\begin{array}{c}\text { Jenis } \\
\text { Kelamin }\end{array}$ & $\begin{array}{c}\text { Skor } \\
\text { OHI-S }\end{array}$ & Kategori \\
\hline 1 & 101 & 11 & $5 \mathrm{C}$ & $\mathrm{L}$ & 1,2 & Baik \\
\hline 2 & 102 & 7 & $4 \mathrm{C}$ & $\mathrm{L}$ & 2,33 & Cukup \\
\hline 3 & 103 & 8 & $5 \mathrm{C}$ & $\mathrm{P}$ & 0,9 & Baik \\
\hline 4 & 104 & 9 & $5 \mathrm{C}$ & $\mathrm{P}$ & 1,1 & Baik \\
\hline 5 & 105 & 11 & $6 \mathrm{C}$ & $\mathrm{P}$ & 3,5 & Buruk \\
\hline 6 & 106 & 8 & 5C & $\mathrm{P}$ & 1,2 & Baik \\
\hline 7 & 107 & 7 & $4 \mathrm{C}$ & $\mathrm{L}$ & 1,5 & Cukup \\
\hline 8 & 108 & 7 & $4 \mathrm{C}$ & $\mathrm{P}$ & 3,3 & Buruk \\
\hline 9 & 109 & 8 & $4 \mathrm{C}$ & $\mathrm{L}$ & 0,9 & Baik \\
\hline 10 & 110 & 9 & $6 \mathrm{C}$ & $\mathrm{L}$ & 3,5 & Buruk \\
\hline 11 & 111 & 8 & $4 \mathrm{C}$ & $\mathrm{P}$ & 1,99 & Cukup \\
\hline 12 & 112 & 9 & $4 \mathrm{C}$ & $\mathrm{P}$ & 3,67 & Buruk \\
\hline 13 & 113 & 8 & $4 \mathrm{C}$ & $\mathrm{L}$ & 1,1 & Baik \\
\hline 14 & 114 & 9 & $4 \mathrm{C}$ & $\mathrm{P}$ & 1,0 & Baik \\
\hline
\end{tabular}




\begin{tabular}{ccccccc}
\hline 15 & 115 & 11 & $5 C$ & $\mathrm{~L}$ & 3,67 & Buruk \\
\hline 16 & 116 & 10 & 5C & $\mathrm{P}$ & 2,67 & Cukup \\
\hline 17 & 117 & 12 & 6C & $\mathrm{L}$ & 3,23 & Buruk \\
\hline 18 & 118 & 13 & 6C & $\mathrm{P}$ & 2,83 & Cukup \\
\hline 19 & 119 & 9 & 5C & $\mathrm{P}$ & 2,67 & Cukup \\
\hline 20 & 120 & 12 & $6 \mathrm{C}$ & $\mathrm{L}$ & 1,1 & Baik \\
\hline 21 & 121 & 8 & 4C & $\mathrm{L}$ & 0,9 & Baik \\
\hline 22 & 122 & 13 & 5C & $\mathrm{P}$ & 2,66 & Cukup \\
\hline 23 & 123 & 13 & $6 \mathrm{C}$ & $\mathrm{P}$ & 1,1 & Baik \\
\hline 24 & 124 & 11 & 4C & $\mathrm{L}$ & 1,2 & Baik \\
\hline 25 & 125 & 13 & 6C & L & 2,99 & Cukup \\
\hline
\end{tabular}

Distribusi kategori OHI-S Anak Tunagrahita

\begin{tabular}{ccc}
\hline Kategori OHI-S & N & $\%$ \\
\hline Baik & 0 & 0 \\
Cukup & 17 & 68,00 \\
Buruk & 8 & 32,00 \\
\hline Jumlah & $\mathbf{2 5}$ & $\mathbf{1 0 0}$ \\
\hline
\end{tabular}

Distribusi kategori OHI-S Anak Tunarungu

\begin{tabular}{ccc}
\hline Kategori OHI-S & N & $\%$ \\
\hline Baik & 11 & 44,00 \\
Cukup & 8 & 32,00 \\
Buruk & 6 & 24,00 \\
\hline Jumlah & 25 & 100 \\
\hline
\end{tabular}

Dari hasil pelaksanaan didapatkan lebih dari separuh anak penderita tuna grahita dan tuna rungu menderita masalah gigi dan mulut. Pembinaan dan penyuluhan serta demonstrasi yang diikuti oleh anak penderita tuna grahita dan tuna rungu serta pendampingnya, ternyata kegiatan tersebut mendapat respons yang baik dari peserta yang terdiri dari anak penderita tuna grahita dan tuna rungu dan pendampingnya (Oktariana, 2019; Rosyid, 2020). Hal ini diketahui dari hasil tanya jawab, dimana sebelum dilakukan penyuluhan dan demonstrasi pendamping belum begitu paham bagaimana cara menyikat gigi yang baik. Evaluasi pencapaian kegiatan ini dilakukan dengan melaksanakan pemeriksaan kesehatan gigi dan mulut beberapa minggu setelah kegiatan penyuluhan dan demontrasi terhadap anak penderita tuna grahita dan tuna rungu dan pendampingnya. 
Dengan telah dilakukan penyuluhan serta demontrasi cara menyikat gigi yang benar, anak penderita tuna grahita dan tuna rungu dan pendampingnya menjadi lebih tahu tentang bagaimana menjaga kebersihan gigi ${ }^{26}$ dan mulut dengan cara menyikat gigi yang baik dan benar untuk dilaksanakan setiap hari.

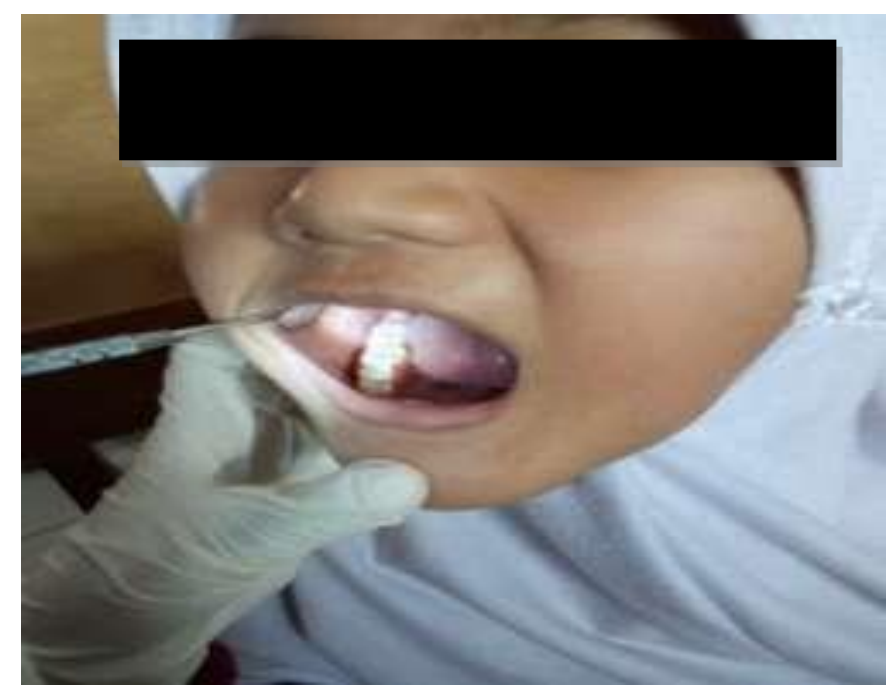

Foto 1. Pemeriksaan gigi dan mulut salah satu penderita tunagrahita

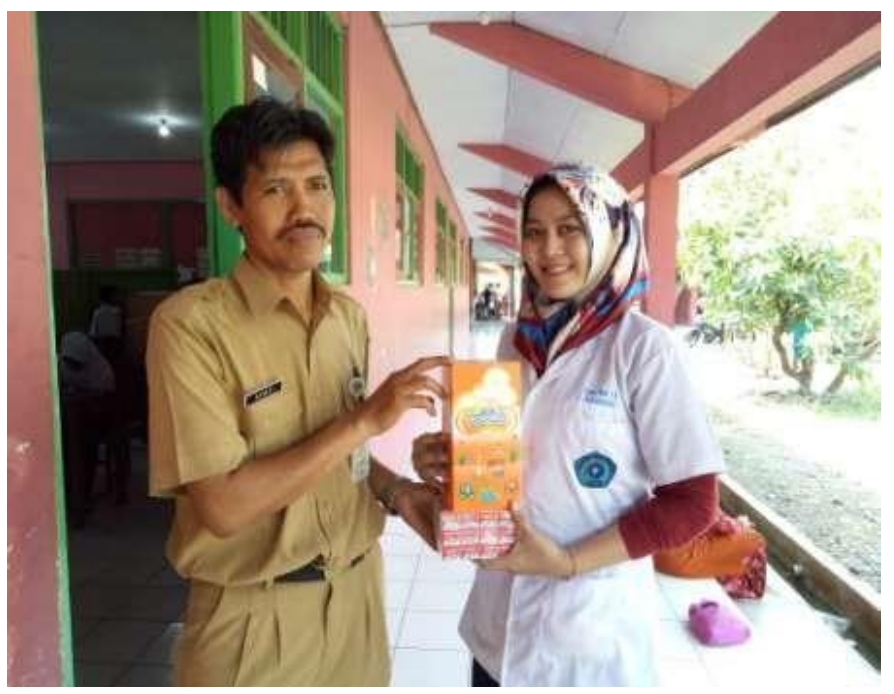

Foto 2. Pemberian kenang-kenangan untuk sekolah 


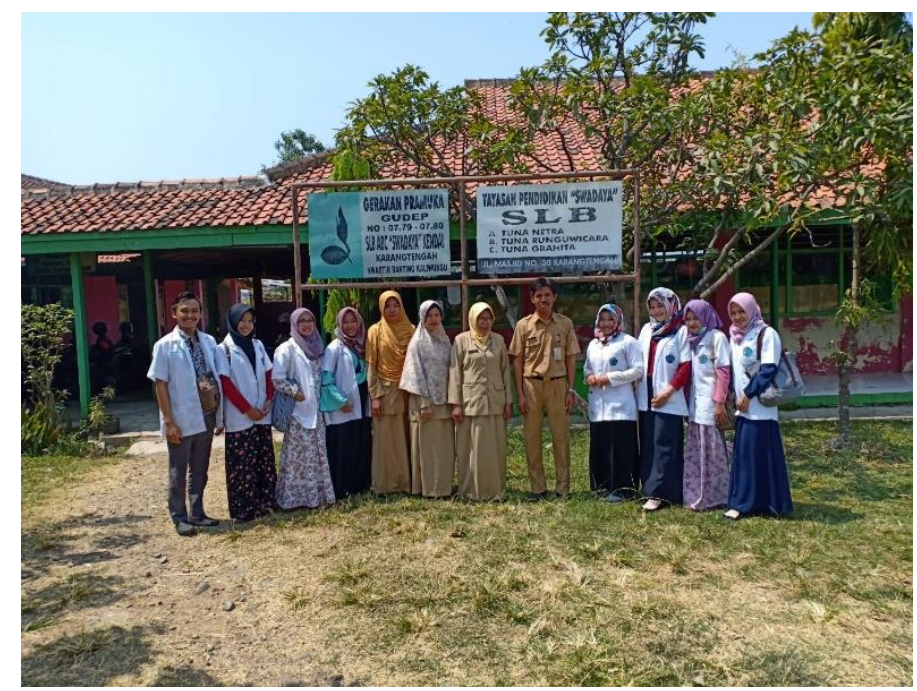

Foto 3. Foto Bersama selesai acara penutupan pengabmas

\section{KESIMPULAN}

Kesimpulan dari kegiatan pengabmas ini adalah Kesehatan gigi dan mulut penderita tuna grahita dan tuna rungu termasuk dalam kategori sedang.

\section{DAFTAR PUSTAKA}

Adhi, Y. K., \& Octavia, A. (2013). Perbedaan Tingkat Kejadian Karies Pada Anak Berkebutuhan Khusus Berdasarkan Jenis Kelamin Di Kelas 1-4 SDLB Widya Mulya, Pundong, Bantul, DIY. Insisiva Dental Journal: Majalah Kedokteran Gigi Insisiva, 2(2), 27-34.

Anwar, R., \& Dinastiti, N. (2022). Upaya Peningkatan Kebersihan Gigi dan Mulut Anak Penderita Down Syndrome Melalui Pemeriksaan, Penyuluhan dan Demonstrasi Menyikat Gigi di SLB Swadaya ABC Kendal. Indonesia Berdaya, 3(1), 105-112.

Askiyah, S. M. (2017). Hubungan Pengetahuan, Sikap Dan Tindakan Orang Tua Menjaga Kesehatan Gigi Dan Mulut Terhadap Indeks Dmf-T Anak Tunarungu SDLB Negeri Ungaran Kabupaten Semarang Universitas Muhammadiyah Semarang].

Dewi, S. R., \& Ners, S. K. (2015). Buku ajar keperawatan gerontik. Deepublish.

Ekasari, M. F., Riasmini, N. M., \& Hartini, T. (2019). Meningkatkan Kualitas Hidup Lansia Konsep dan Berbagai Intervensi. Wineka Media.

Kristianto, J., Priharti, D., \& Abral, A. (2018). Efektifitas Peyuluhan Kesehatan Gigi Dan Mulut Dengan Media Video Melalui WhatsApp Dalam Meningkatkan Derajat Kesehatan Gigi Dan Mulut Di Panti Asuhan Yos Sudarso Jakarta. Quality: Jurnal Kesehatan, 12(1), 8-13.

Kurniawan, I. (2017). Hubungan Parenting Self-Efficacy dengan Tingkat Stres Ibu yang Memiliki Anak Tunagrahita di Sekolah Luar Biasa (SLB-C) Kabupaten Jember.

Lisinus, R., \& Sembiring, P. (2020). Pembinaan Anak Berkebutuhan Khusus (Sebuah Perspektif Bimbingan Dan Konseling). Yayasan Kita Menulis.

Maryam, S. (2008). Menengenal usia lanjut dan perawatannya. Penerbit Salemba. 
Mawardiyanti, D. (2012). Gambaran Kebersihan Mulut Dan Karies Gigi Pada Anak Penderita Down Syndrome Di SDLB Negeri Patrang Dan SLB Bintoro Jember (Penelitian Deskriptif).

Oktariana, A. (2019). Pemenuhan Hak Pilih Disabilitas Mental Oleh KPU Provinsi DKI Jakarta Pada Pemilu 2019 (Studi Kasus: Panti Sosial Bina Laras Harapan Sentosa 1) Fisip UIN Jakarta].

Prasko, P., Santoso, B., \& Sutomo, B. (2016). Penyuluhan metode audio visual dan demonstrasi terhadap pengetahuan menyikat gigi pada anak sekolah dasar. Jurnal Kesehatan Gigi, 3(2), 53-57.

Rosyid, A. (2020). Implementasi Pembelajaran PAl dalam Pendidikan Inklusi: studi multisitus di SMAN 1 Gedangan dan SMAN 4 Sidoarjo UIN Sunan Ampel Surabaya].

Taftazani, R. Z. (2015). Efektivitas Metode Drill Terhadap Pengetahuan, Sikap, Keterampilan, Dan Oral Hygiene: Studi Kasus pada Penyandang Tunanetra di SLB Kota Semarang Program Pascasarjana UNDIP].

Tulangow, G. J., Pangemanan, D. H., \& Parengkuan, W. G. (2015). Gambaran status karies pada anak berkebutuhan khusus di SLB YPAC Manado. e-GiGi, $3(2)$.

Zakiyyah, S. (2019). Gambaran Dukungan Orangtua Tentang Tingkat Kemandirian Personal Hygiene Pada Anak Tunagrahita di Sekolah Dasar Luar Biasa C Kota Bandung. 